\title{
Trends of the Arabic Research on the Nature of Science
}

\author{
Suad Alhamlan ${ }^{1}$, Haya Aljasser ${ }^{1}$, Asma Almajed ${ }^{1} \&$ Sozan Hussain Omar ${ }^{1}$ \\ ${ }^{1}$ Department of Curriculum \& Instruction, King Saud University, Riyadh, Saudi Arabia \\ Correspondence: Suad Alhamlan, Department of Curriculum \& Instruction, King Saud University, Riyadh, Saudi \\ Arabia. E-mail: suadalhamlan@gmail.com
}

Received: January 2, 2018

Accepted: February 15, 2018

Online Published: April 27, 2018

doi:10.5539/ies.v11n5p110

URL: https://doi.org/10.5539/ies.v11n5p110

\begin{abstract}
The paper investigates the trends of the Arabic research with the emphasis on the nature of science. Hence, a descriptive analytical approach, both qualitative and quantitative forms, was used to explore 42 online journals and articles. The research sample was defined by online journals and articles cover the question of the Nature of Science (NOS) in the Arabic setting. The data collection tool has implemented a content analysis checklist that contains three sections the fields of study section, the subjects of each field, as well as methods and procedures. The results taken from the data analysis have shown that most Arabic researchers focus on the curriculum, teaching and learning environments and their improvement, the use of new teaching methods, students' understanding of NOS, as well as teacher's knowledge and teaching strategies. Also, many researchers have used descriptive methods and techniques. The research findings suggest that Arabic NOS has been done by teaching science through education. The paper provides recommendations to ensure greater government involvement in establishing science centers that attract graduating students in science learning and relevant projects.
\end{abstract}

Keywords: nature of science, NOS, Arab research, scientific

\section{Introduction}

\subsection{Introduction of the Problem}

The essence of the Nature of Science (NOS) instruction emphasizes the development of a scientific culture since the entry to science education should be done through "education through science" rather than "science through education" (Holmqvist \& Olander, 2017, p. 4). Also, it is better to rely on a structured model of the NOS education that is based on the activity theory instead of relying on logic, and this includes understanding the NOS with the achievement of clearly set goals in the personal dimension. Moreover, it is essential to take into consideration the development of intelligence and communication skills, as well as positive trends that focus on the interest in collaborative learning and decision-making in scientific and social situations (Holmqvist, 2011). Furthermore, the NOS is regarded to be an important element that enables to achieve citizenship and the development of scientific and technological culture (Abd-El-Khalick, 2012).

The NOS understanding has long been emphasized as a key factor in the scientific knowledge. Lederman and Abell (2014) present five arguments for the inclusion of the Nature of Science in science teaching. It is explained by the fact that the NOS helps the learners (a) comprehend the process of science, (b) take an active part in debates and decision-making processes related to the socio-scientific matters; (c) internalize an appreciation of science as a major component of contemporary culture, (d) be committed to the standards of the scientific community, and (e) be aware of the science content.

Although the understanding of the NOS is an essential element of the scientific culture, there is still much evidence that public education students and university students have little understanding of the NOS (Abd-El-Khalick, 2014). This is closely related to the lack of interest in teaching the NOS during formal education, keeping away from clarifying the essence of science, and its interpretation of the cosmic, natural and environmental phenomena (Jones et al., 2013).

The teaching of the NOS is still a major challenge in the field of science education, which calls for the development of educational guides for teachers based on the standards of educational science curricula, scientific research and field experience to help them teach the NOS, changing their perceptions of the scientific knowledge (Marton, 2015). 


\subsection{Importance of the Problem}

The current situation of science instruction shows that most teachers are interested in providing a large amount of scientific knowledge and training students to solve the issues. However, the primary focus of students is to retain the largest amount of information and evaluation methods, focusing on measuring their ability to memorize without employing the mind (McComas, 2015). This is contrary to the NOS, which is based on surveying, thinking, and understanding, linking with natural phenomena, and interacting with the society issues.

The research in the NOS is one of the essential fields of the educational research and it intervenes with other fields such as natural sciences, science history, and philosophy (Lederman \& Abell, 2014). The NOS research pays attention to the teaching of science issues. Also, it answers the questions raised in the educational domain and contributes to finding solutions to the existing problems. The history of the research in the NOS is relatively short, and it means that more studies are needed to get a better understanding of the problems related to the NOS (Jones et al., 2013). In the United States of America, the research in this field started in the last century, while in the United Kingdom, the research in NOS started in the sixties of the past century, where the specialized journals and periodicals appeared. As a result, a number of the universities started to offer postgraduate programs in the NOS. By the end of the twentieth century, the NOS research has witnessed an extensive interest due to the emerging amount of knowledge in this field.

The trends in NOS research were linked to the reform movements, as well as the developments in science curriculum and in the contemporary educational theories. Although there were some changes in the trends of the NOS research from time to time due to the change in the cultural and social contexts, there is a need for a critical and comprehensive review for the research endeavors. Also, there is a need to learn about the status quo of the NOS research in terms of the fields of study, the methodology used, and the results gained.

The critical and comprehensive review of the NOS research requires the criteria which include all the fields of research. Different classifications have emerged, including teachers' preparation, the science curricula, students, classrooms, and the school environment. However, other fields such as teaching methods, fields of the study, assessment, educational technology, and student perceptions have also emerged as the NOS research areas. On the other hand, Van Dijk (2014) suggests a number of issues that should be involved in analyzing the NOS research, including the concept of NOS, science epistemology, science instruction epistemology, research methods, science instruction goals, sex, quality, science instruction context, teachers' professional development, evaluation, teaching design, and science curriculum.

\subsection{Purpose and Research Questions}

The purpose of this research is to explore the trends of the Arabic research in the nature of science. Hence, the research aims to examine the NOS in the Arabic research, focusing on the study, research methodologies, teaching strategies, teaching problems, teaching practices, and teaching improvement undertaken in the NOS Arabic research.

The research attempts to answer the following questions:

1) What are the trends of Arabic research in the Nature of Science in terms of the fields of the study?

2) What are the trends of Arabic research in the Nature of Science in terms of the subjects of each field?

3) What are the trends of Arabic research in the Nature of Science in terms of research methodology?

4) What are the trends of Arabic research in the Nature of Science in terms of teaching strategies, teaching problems, teaching practices, and teaching improvement?

\subsection{Relevant Scholarship}

In the view of the importance of reviewing and analyzing the research carried out in the NOS, as noted earlier, this topic attracted the attention of a number of researchers and educators. The increased interest can be related to the most prominent attempts to review the literature of scientific education and the emergence of three books on the NOS in the past two decades. The first book, titled "Handbook of Research on Science Teaching and Learning (HRSTL)" was written by Gabbel in 1994, focuses exclusively on the research conducted in the United States of America. The second book, titled "The International Handbook of Science", was written by Fraser and Tobin in 1998. Despite the participation of a group of researchers at the global level in the preparation of this guide, the aim was to review the research in a specific period of time. The third book, titled "Research on Science Education (HRSE)", was written by Abel and Lederman in 2007. This book includes a comprehensive review of the research in the NOS at the global There are many international studies conducted to review the main trends of the NOS research. Hence, Tsai and Wen (2005) investigated the trends of the NOS research in three scientific periodicals. 
They analyzed the studies published in the period from 1998 to 2002 in terms of the research type and the research subject. The findings showed that $86.9 \%$ of the studies were experimental, $9.4 \%$ were case studies, $0.7 \%$ were theoretical, $1.6 \%$ were review studies, and $1.4 \%$ were belonged to other types. In terms of research areas, the most three common areas were learning and students' understanding (24.7\%), the learning context and characteristics of students (17.9\%), and the field of culture and society (14.3\%).

Another study was conducted by De Jong (2007) to analyze the published NOS research that occurred in 2005 in the international journals of IJSE, JRST, and SE. Fourteen research areas were identified: the students' understanding, the students' attitudes, the students' learning processes, the teacher's knowledge of scientific content, the teacher's pedagogic knowledge, teaching strategies, the development of teachers' knowledge of scientific content, the development of pedagogical knowledge of a teacher, laboratory work, issues of science, technology and society, problem solving, modelling and models, information technology, and gender. The findings of the study showed that the most common research areas were the students' understanding, the laboratory work, the teacher's knowledge of scientific content, issues of science, technology, and society.

Furthermore, Lee et al. (2009) studied the orientations of the NOS research in the international journals of IJSE, JRST, and SE from 2003 to 2007 and compared the findings with the findings of Tsai and Wen (2005). The scientists successfully showed a great similarity between the two studies in terms of the research types. It was revealed that the proportion of experimental studies equaled $87.8 \%$, the case studies represented $4.1 \%$, the theoretical research was 3.5\%, the review studies showed 3.0\%, and the other kinds of research equalled $1.6 \%$. Also, the findings showed that the common trends of the NOS research focused on the teacher's knowledge, professional knowledge, teacher's thinking, learning behavior, and teaching methods.

In the Arabic context, very few studies focus on the trends of NOS research. Only two Jordanian studies aimed at investigating the trends of NOS research. Hence, Al-Omari and Nawafleh (2011) identified the reality of research in scientific education in Jordan during the period between 2000 and 2009; the primary focus made on was the fields of research and the types of research used. In order to achieve the objectives of the study, the scientists analyzed 188theses abstracts in the field of science education and 42 abstracts of the published educational journals issued by the Jordanian universities for the same period 2000-2009. The research material was classified according to the research areas and types of research, using specially designed tools. The results showed that $72.8 \%$ of the scientific education research covered the field of teaching and learning, and mostly concentrated on the research methods and strategies of teaching, $20.2 \%$ dealt with the science teacher and the most of them focused on the teacher's professional knowledge, and $7 \%$ dealt with the textbooks of school science. In terms of the research types, $61.4 \%$ were experimental, $19.3 \%$ were descriptive, $16.7 \%$ were comparative, $2.2 \%$ were correlational, and $0.4 \%$ were historical ones.

Also, Sabrini and Al Razhi (1999) discussed the reality of science research conducted at the Jordanian universities. They studied the abstracts of the science theses written by the representatives of the Jordanian universities during the period from 1971 to 1988 . The scientists classified the collected theses according to the research type (theoretical, practical, evaluative, and descriptive). In addition, they classified the research fields into (the teacher preparation, the science curriculum, the learners, the teacher, and the semester variables). The findings showed that the science research focused on the descriptive and practical research, and it failed to stress the theoretical or evaluative research. Also, it was shown that the science research focused on the learner and science curriculum.

Thus, the trends of the NOS research have received a considerable attention at the global level. However, in the Arabic context, the NOS research trends do not get proper attention. It has impacted the teaching and learning of science in the Arab schools. Nowadays, there should be more interest in the NOS research due to its importance and benefits. Since there is an expansion in the various science education programs, constantly increasing number of programs offered by educational institutions, and a variety of $\mathrm{PhD}$ programs in the specialization of science curricula and teaching methods, a greater focus should be made on the NOS research in the Arabic context. With a view to identify a framework for this issue of research and to direct the efforts of the NOS researchers and institutions, there is a need to direct the attention towards what has been achieved in this area of research in the Arabic context. This will substantially contribute to the guiding of the future NOS research.

\section{Research Method}

A research method has been defined as the "the manner in which the research conducts the research, collects data, and draws the conclusion" (Kasper, 2000, p. 12). The interest in the research methods that fit a certain discipline has been the interest of many scholars over the years. Watts (2003) asserts that the selection of the research methodology that fits the research objectives and answers the research questions is a major component of the research success. Also, Golato (2002) reports that the research methods should be selected according to the criteria 
of the research topic, the achievement of set goals, the nature of the research sample, and the branch of knowledge to which the topic belongs.

The majority of the studies that investigated the NOS used a mix of the qualitative and qualitative methods (Sabrini \& Al Razhi, 1999; Al-Omari \& Nawafleh, 2011; Abd-El-Khalick, 2012). Most researchers have agreed that the qualitative research in the NOS studies gives the researcher the ability to control the variables and to evaluate the representation of the nature of science in the science books. Also, De Jong (2007) mentions that a quantitative study of the NOS is best suited to investigate the NOS trends since it reveals insights about the different aspects of the nature of science. Therefore, this research uses the content analysis and explores the NOS trends in the Arabic research both qualitatively and quantitatively in terms of focus of the study, research methods, teaching strategies, teaching problems, teaching practices, and teaching improvement.

\subsection{Data Collection}

Two data collection methods were used in this research: secondary data and primary data collection methods.

\subsubsection{Secondary Data Collection Tools}

The secondary data collection methods used in the study are:

- Library sources (journal articles, books, and reports);

- Electronic sources represented by databases and web pages.

\subsubsection{Primary Data Collection Tools}

The research uses a content analysis checklist that consists of four sections: (1) the fields of study, (2) the subjects of each field, (3) research method, (4) and data collection procedures. Below is a description of the components of each section:

- The fields of the study: it consists of sub-sections (teaching science, science learning, the teacher, the students, the curriculum, and the school).

- The subjects of each field: it consisted of 6 sub-sections. Each sub-section includes a number of items described below:

- Teaching science: it includes teaching strategies, teaching problems, teaching practices, and teaching improvement.

- Science learning: it includes learning environment, learning difficulties, and learning improvement.

- Teacher: it contains teachers' perceptions, teachers' knowledge, teachers' understanding, teachers' training, and teachers' problems.

- Students: it contains students' understanding, students' abilities, students' characteristics, and students' problems.

- Curriculum: it includes the curriculum topics, class activities, new teaching methods, extracurricular activities, using technology, and curriculum flaws.

- School: it contains the school environment, school personnel, and equipment and supplies).

The content analysis checklist was designed based on the NOS previous studies and literature (Tsai \& Wen, 2005; Duite, 2007; De Jong, 2007). The checklist is self-administered by the researchers on the corpus that served as the research sample. The researchers calculated the frequency and percentage of the occurrence of each of the above sections in order to identify trends of NOS in the Arabic research.

\subsection{Checklist Validity and Reliability}

Validity means that the research tool is suitable for the purpose for which it was designed. The researchers achieved the validity of the checklist by submitting it to a number of experts and requesting their opinions on the suitability of the checklist to the research objectives. The researchers made the due amendments to the checklist based on the experts' opinions and produced the checklist in its final form (Appendix A).

Reliability is the extent to which the checklist gives the same result (APA, 1985). In this research, the scientists used Cronbach's Alpha coefficient to assess the reliability of the checklist. The reliability coefficient was 0.821 and it is a high reliability rate.

\subsection{Sample Selection}

An accurate determination of the research population is vital in order to collect the required data for the research problem. While population is the entire set of participants of interest, a sample is a representative subset of the 
population. The population of this research comprised of journal articles, an emphasis is made on the investigation of the nature of science in the Arabic context and assessed the trends of these studies. The research sample consisted of the online journal articles that investigated the nature of science in the Arabic context published in the period from 2011 to 2017. The number of collected research papers equalls 42 journal articles. Analysis of the selected articles has shown that some of them had several foci. Hence, they were additionally evaluated to define the main focus and decide whether they can be used for in the current research. As a result, all of them appeared to have the primary focus on the issue under investigation.

Each article that contained several foci, similar to the foci of the current research, was examined to trace the most essential aspect discussed by the author. It enabled to find the variables and their relevance to our study. Then, the researcher analyzed the question of the studies and concentrated on the main focus and subjects covered in each of them. It assisted in defining the primary focus, similiarity of the research questions and variables, as well as relevance to the current study.

\subsection{Limitations of the Study}

The research is limited to the study of the trends of the Arabic research in the nature of science. In particular, the research focuses on the journal articles that investigate the nature of science in the Arabic context in the period from 2011 to 2017). The collected NOS research includes all the educational levels from the elementary stage until the university stage. The researchers use only one data collection tool, the content analysis checklist, due to its suitability to the research objectives. Furthermore, the data collection process is self-administered and the research data is self-analyzed.

\subsection{Procedure}

The researchers used the following procedures to conduct the study:

- The researchers made a list of 42 local and international online journals relevant to science education. The articles that discussed the nature of science in the Arabic context were selected by the researcher.

- The researchers only selected the journal articles that covered the nature of science in the Arabic context published in the period from 2011 to 2017.

- The journal articles are downloaded from the digital university libraries and from the websites of the scientific journals such as the Jordanian Journal of Educational Science, International Journal of Science Education, Journal of Technology and Science Education, and Research in Science \& Technological Education.

- The researchers prepared a content analysis checklist to identify the trends of the nature of science research in the Arabic context. The validity and reliability of the checklist were verified as mentioned above.

- The researchers focused on the abstracts of the collected articles and classified each article as per the sections of the checklist. If the information mentioned in the abstract was not sufficient, the researchers got back to the full article. All the articles were classified in accordance with the checklist sections.

The procedure of article selection has enabled to realize that there are many valuable online articles that can serve as a basis of any research, in particular the NOS. The online articles have helped to get a better understanding of the nature of science research in the Arab context.

\subsection{Data Analysis}

The selection of the statistical treatment of a research results depends on the research questions and objectives. Frequency and percentage were used as key statistical tools in the current study. The frequencies and percentages of each item in the checklist were calculated. The data were tabulated and represented in charts in order to visually represent the findings in a more clear way. Then, the findings were discussed and analyzed in light of the literature review. The researchers presented recommendations and suggestions based on the research findings.

\subsection{Research Design}

The research design has enabled to collect the data and properly analyze them. There are two paradigms that characterize research, they are qualitative and quantitative (Glass \& Hopkins, 1984). The qualitative paradigm focuses on the examination of subjective data that usually deals with the people's perceptions. The primary aim is to understand and explain these perceptions, providing a deep insight and knowledge. This paradigm makes an emphasis on what can be measured. It involves the collection and analysiz of the objective (often numerical) data that can further make statistics (Robson, 1993).

Another classification of research types was provided by Robson (1993), who identified exploratory, descriptive, 
and analytical research. Hence, a descriptive research is used to obtain information concerning the current status of the phenomena to describe what exists with respect to variables or conditions in a situation (James, 2001). The methods involved range from the survey, which describes the status quo, the correlation study, which investigates the relationship between variables, to the developmental studies, which seek to determine changes over time. A descriptive research can be either quantitative or qualitative (James, 2001). It can involve the collection of quantitative information that can be tabulated along a continuum in numerical form. Descriptive research involves gathering data that describe events, organizing, presenting in tables or charts, and describing the data collection process (Salkind, 2009). An analytical further explains the reasons behind a particular thing, event, or occurrence by discovering causal relationships. It can be quantitative or qualitative, depending on whether the focus is on exploring factors which can be assigned a definitive value, or factors which cannot be given such a definitive value, such as attitudes or beliefs (Salkind, 2009).

The current research uses the descriptive analytical approach that describes and analyses the trends of nature of science in the Arabic research. The research design constructed here is based on the questions formulated.

\section{Research Results}

The data from the content analysis checklist was based on 42 online journal articles that investigated the nature of science in the Arabic context and assessed the trends of these research papers. The data from the content analysis checklist was analyzed and recorded in three sections (fields of the study, the subjects of each field, and methods and procedures) as explained below.

\subsection{Fields of the Study}

The analysis of the identifying fields of study was directed towards the school, curriculum, students, teacher, science learning and teaching science. The received results suggested that more studies were directed towards the curriculum which recorded the highest percentage of $23 \%$ in the sample. The second field was science learning which attracted $22 \%$, the third was the students, which attracted $20 \%$, followed by teaching science which attracted $18 \%$, the teacher, which attracted $14 \%$, and finally the school which attracted the smallest percentage as shown in Figure 1 below.

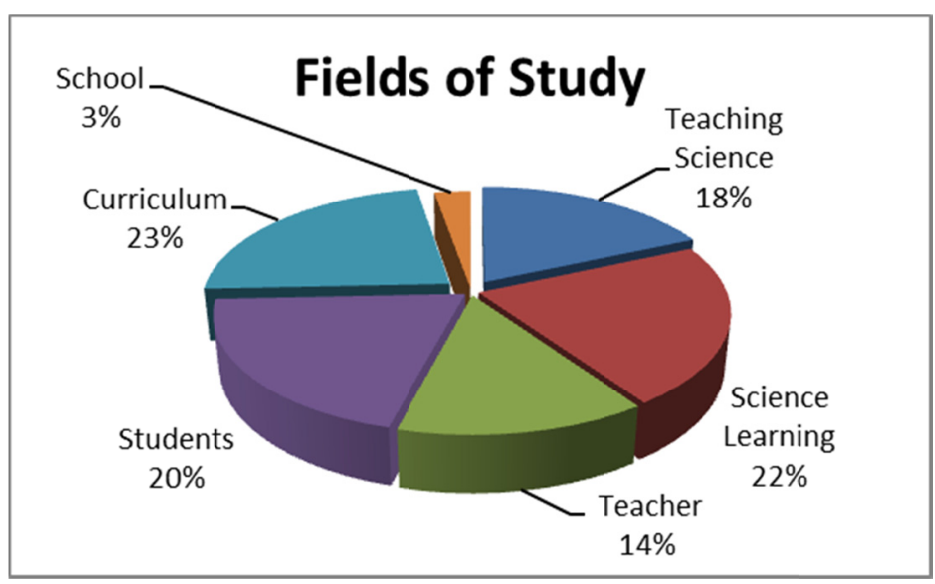

Figure 1. Arabic researchers' trends in the NOS in terms of fields of study

The results of the first research question suggest that there is a greater emphasis on the Arabic research in the Nature of Science in terms of the focus of the study by noting the curriculum study dominance that attracted the highest percentage. However, the difference between researchers directed towards the curriculum, students, and science learning did not differ significantly as there was only a $3 \%$ difference between them. The researchers directed towards teaching science, and their studies were averagely given the mean of the total fields of study. It can be concluded that the greatest focus of the Arabic researchers was made on the curriculum and science learning, while moderate research efforts were directed towards a teacher and teaching science. At the same time, very little research was conducted to investigate the question of school. The above findings are also consistent with the results received by Tsai and Wen (2005), who identified learning and students' understanding, further focusing on the learning context and characteristics of students as the main research areas. This study records the curriculum as the main study area which is represented by the learning context in Tsai and Wen (2005) studies. 


\subsection{Subjects of Each Field}

Having identified the field of the study as discussed in the previous section, the study sought to identify elemental aspects of the nature of teaching in each of the identified fields of study.

\subsubsection{Teaching Science}

The teaching science field has enabled to reveal teaching problems, teaching strategies, teaching practices, and teaching improvements as the subjects that the researchers were targeted at. The findings suggested that teaching improvement was the mostly studied subject (35\%), while teaching practices equaled $32 \%$, and teaching strategies $24 \%$. The least researched subject was teaching problems and it took only $9 \%$ of the total sample. The results are represented in Figure 2.

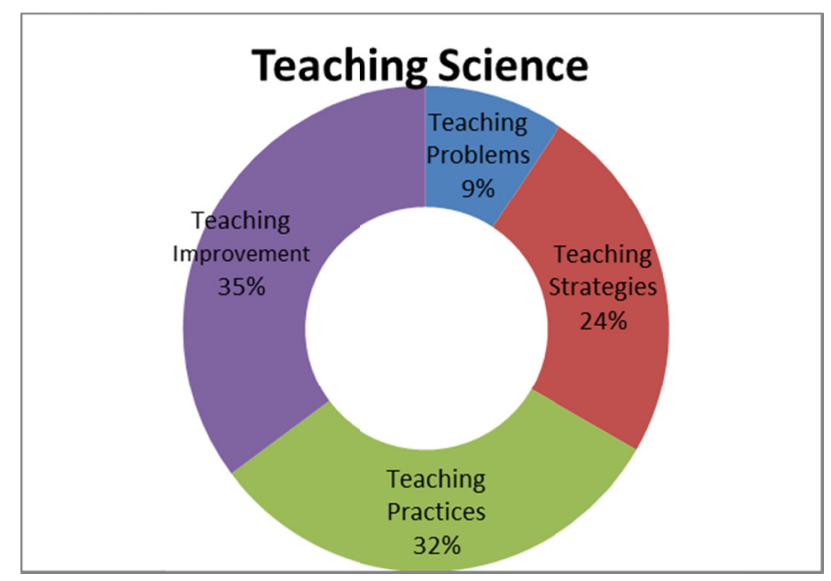

Figure 2. Research directed towards teaching science

The subjects of study represented in the figure above support the literature review directed towards the challenges of the NOS teaching by Marton (2015), who proposes improvement measured through the development of educational strategies for teachers. These strategies can only be identified through the research that assists in identifying underlying teachers, problems, existing teaching strategies, teaching practices, and the improvement of teaching. Therefore, this study identifies the existing number of studies that focus on the development of educational guidelines based on the assessment of critical elements in the shpere of teaching science.

\subsubsection{Science Learning}

Subjects identified under science learning included learning improvement, learning environment, and learning difficulties. In regards to science learning, results revealed that more research was directed towards the learning environment and learning improvement where both recorded $46 \%$ each. The research that focused on learning difficulties recorded a minimal percentage of 8 . The received results are represented in Figure 3.

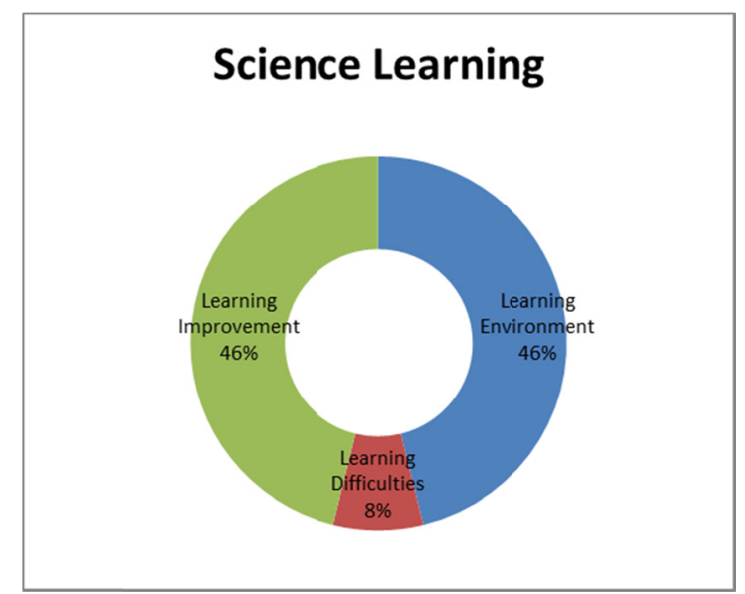

Figure 3. Research directed towards science learning 


\subsubsection{Teacher}

In regards to the teacher, the checklist was inclined to the identification research subjects within the following contexts; teachers' perceptions, teachers' knowledge, teachers' understanding of the NOS, teachers' professional development, and teachers' problems. The findings have enabled to reveal that the teacher's knowledge has been the most researched subject ( $27 \%$ of the total sample). Other researched subjects indicated $22 \%$ for teacher's perceptions, teachers' understanding of the NOS equaled $23 \%$, teachers' problems reached $15 \%$, and teachers' professional development bottomed the list with $13 \%$. These results are represented in Figure 4.

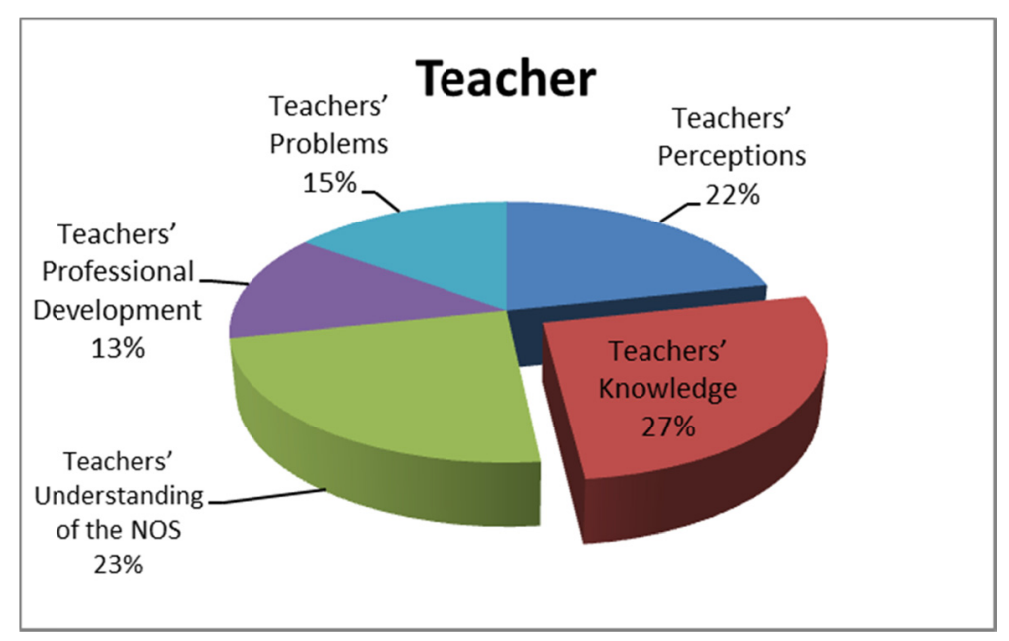

Figure 4. Research directed towards the teacher

The received findings are consistent with the international study conducted by De Jong (2007) who identified the teacher's knowledge of scientific content and the teacher's pedagogic knowledge as the main study areas. A similar study was carried out by Lee et al. (2009) who found that the NOS research focused on the teacher's knowledge, teacher's thinking, and professional knowledge. Similarly, Jordanian studies conducted by Al-Omari and Nawafleh (2011) identified teacher's professional knowledge as the study area with significant emphasis on the professional knowledge of teachers.

\subsubsection{Students}

The subject areas directed towards the student were characterized by the students' problems, students' understanding of the NOS, students' perceptions, and students' abilities. However, it has been found that the studies are concerned more with the students and their understanding of the NOS as opposed to their problems. The statistics showed that $40 \%$ of the sampled researchers were directed towards the student's understanding of the NOS, while only $10 \%$ sought to examine the students' problems. Other subjects identified by the researchers were student's perceptions that reached $29 \%$, and students' abilities equaling $29 \%$. 


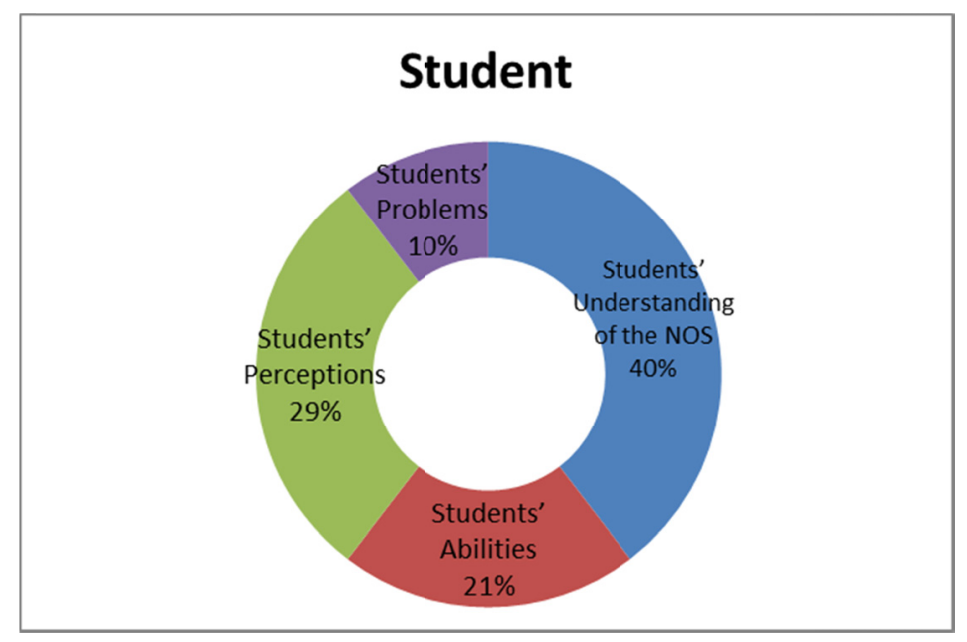

Figure 5. Research directed towards the students

The findings represented in the figure above are consistent with the study conducted by De Jong (2007) who identified students' understanding, students' attitudes, and students' learning processes as the research areas. By identifying the student's understanding of the NOS as the main area of research, the study supports the literature review by showing the outcome of the teacher's teaching interests which are based on the ability to provide large amounts of information which enables students to memorize without using any mental efforts (McComas, 2015).

\subsubsection{Curriculum}

Research into the curriculum recorded significant subjects that were connected to class activities, curriculum topics, new teaching methods, extracurricular activities, curriculum flaws, and the use of technology. Also, research that focused on the curriculum topics was the most researched $(31 \%$ representative share of the total sample), while the least researched subjects were related to the use of technology and class activities that reached $8 \%$ each of the total sample. Other subjects identified by the research included curriculum flaws that recorded $25 \%$, and new teaching method that recorded $28 \%$. It is important to note that the study did not find any research directed towards the extracurricular activities.

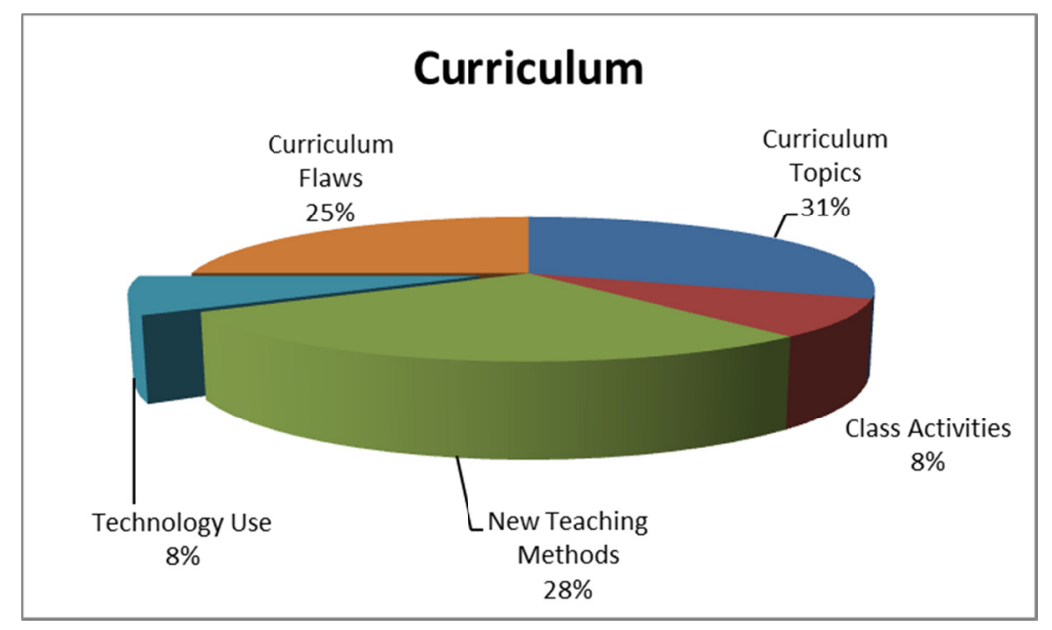

Figure 6. Research directed towards the curriculum

The above findings are consistent with Jordanian studies conducted by Al-Omari and Nawafleh (2011) whose investigation on the trends of the NOS research found out that a significant amount of research concentrated on the research methods and strategies of teaching. The ranking of technology as the lowest subject of interest coincides with the results represented by with the findings of De Jong (2007) who identified the issues of science and 
technology as the most researched areas.

\subsubsection{School}

The study subjects in regards to the school were represented by school personnel, equipment and supplies, as well as the general school environment. Among the subjects identified, no research was directed towards the school personnel. A considerable amount of research (see Figure 7) was directed towards the school environment which recorded $60 \%$, and some targeted equipment and supplies which reached $40 \%$.

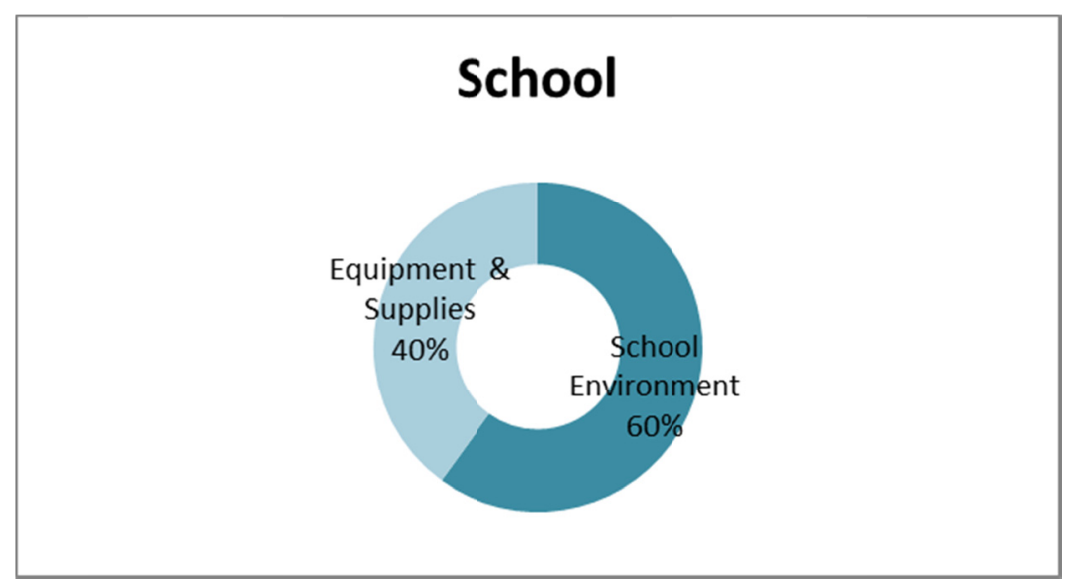

Figure 7. Research directed towards the school

\subsection{Methods and Procedures}

The study identified descriptive approach as the most common research method and procedure used in the Arabic research. The results are represented in Figure 8. The research samples were categorized in accordance with the use of the research approach. Hence, 22 used a descriptive approach, 11 a content analysis, 2 a qualitative research approach, 2 used a quantitative approach, 2 applied a survey approach, and only 1 implemented a case study. No studies were found to use mixed approach, historical approach, correlational approach, comparative causal, and documentary approach.

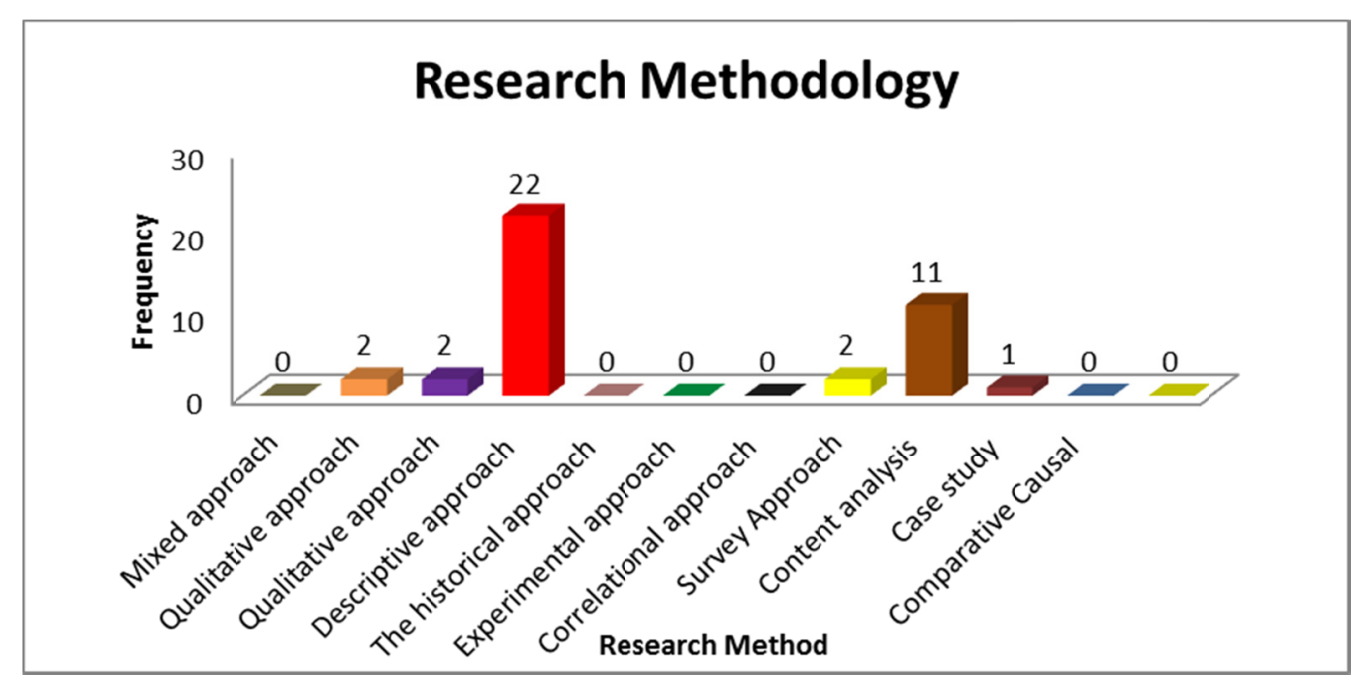

Figure 8. Trends in the Arabic NOS researchers on research methodology

The results represented in Figure 8 enable to answer the second research question, determining the trends of the Arabic NOS research in terms of the research methodology. The findings indicate some consistency with similar 
studies conducted by Tsai and Wen (2005) who, after analyzing three periodicals concluded that a majority of the NOS research reviewed was experimental and a considerable number were case studies. In general, the study shows significant similarities with prior studies conducted by Tsai and Wen (2005) and Lee et al. (2009). This may be related to the identification of experimental studies, case studies, and theoretical (descriptive) approaches as the main research methods applied by the NOS researchers. The study carried out by Al-Omari and Nawafleh (2011) also identified the dominance of experimental studies among the NOS researchers, followed by the experimental, descriptive, comparative, correlational, and historical ones.

While the experimental approach appears to dominate, the current research results indicate that the dominant use of experimental research that is applied after descriptive approaches. Also, a notable decrease has been identified in the use of case studies compared.

However, Al-Omari and Nawafleh (2011) present a scenario that is almost similar to the results represented in Figure 8 . The trend could perhaps be explained by the context through which the two studies are carried out, given that Al-Omari and Nawafleh (2011) was a Jordanian study which is similar in the context with the current study, while the rest were international studies. Moreover, the studies conducted by Sabrini and Al Razhi (1999) in Jordan also prove the focus of science studies on the descriptive approach. While there may be the omission of previous methods and procedures recorded from the previous studies such as review studies, it is important to mention that the application of comparative causal, correlational, historical, and mixed approach in the NOS research rarely exists.

The results were instrumental in affirming that most Arabic research used the descriptive approach, while a considerable amount of research papers used experimental approach and content analysis. The identification of the descriptive approach as opposed to theoretical and evaluative as the main angle taken by most Arabic NOS research actually affirms the notion that science is done through education which should not be the case. The trend is possibly explained by the approach of more studies on the learner and the curriculum. The above findings that trends in the NOS research are not given sufficient attention which could negatively impact teaching and learning science.

\section{Discussion}

The research statistics have determined that the trends of the Arabic research in the nature of science are currently in a crisis. Substantial evidence reveals that science education at different educational levels is not adequate enough to prepare students to survive in the contemporary scientific and technologically advanced environment. The interests in and attitude towards science appears to be at a standstill in the Arabic context. Most of these failures could be attributed to the poor quality of teaching. Besides, the alarming fact is that there appears to be confusion about recommended teaching approaches concerned with improving the quality of science education. While the burden seems too heavy to carry, there is still hope for the Arab world which we believe has a proud history of scholarship. The existence of two Jordanian studies by Al-Omari and Nawafleh (2011) as well as Sabrini and Al Razhi (1999), which aimed at establishing the NOS research trends in the region, instill hope.

The direction given towards the teaching of science could be one of the reasons attributed to its poor response in the region. From the literature review, it is evident that even with the existence of some research on the NOS, greater focus was made on descriptive and practical models as opposed to theoretical and evaluative models (Sabrini \& Al Razhi, 1999). Again, from the curriculum, it appeared that more efforts were directed towards curriculum topics as opposed to using technology and class activities. This concept, according to McComas (2015), pumps scientific information into student by providing large amounts of information without developing any means to aid the student in learning.

This may be one factor that could be attributed to the diminished interests of the NOS among students. Concept mapping is considered to be the best teaching and learning strategy that has proven to enhance learners' scientific knowledge. BouJaoude (2011) states that concept maps play a significant role in curriculum mapping when separating important content. Concept maps have also been used as assessment and instruction tools due to their ability to construct a more student-centered approach by allowing students to construct their own knowledge using the teacher's guidance. Furthermore, Lederman and Abell (2014) suggests that scientific knowledge is anchored on five pillars which assist student in (a) understanding the process of science, (b) participating in debates and decision-making (c) internalizing and appreciating science as a component of contemporary culture, (d) showing commitment to the standards of the scientific community, and (e) being aware of the science content.

The Arab world appears to be facing significant issues associated with the approaches in teaching science and the professional development of teachers. Given the teacher and student challenges identified in the learning process, it was evident that the methods and procedures taken by most of the researchers were not holistic. This was 
elucidated by the lack of a historical approach, mixed approach, comparative causal, and correlational approach in the NOS research among the sample. It has been found that most Arabic research focussed on descriptive and experimental research methodologies. Contemporary advances in the cognitive science research and psychology have changed the nature of teaching science to a more practical one as opposed to theoretical. Students no longer rely on science educators to fill their brains with information, but rather want to learn through experience by relating new information to what they already know (BouJaoude, 2011).

Trends in the Arabic NOS research directed towards the students revealed minimal efforts in identifying student's problems and perceptions. It should be noted that learners have developed the ability of identifying and analyzing problems and exploring solutions in practical situations through experimentation and re-evaluation of problem solutions (BouJaoude, 2011). Therefore, more research should focus on learner's attitudes that will eventually permit them to use their classroom knowledge in contribution towards the field. On the other hand, teachers should have professional knowledge in order to offer generative learning and involve learners in meaningful learning.

The study results indicate that there are no studies conducted along extra-curriculum activities under 'Curriculum' and school personnel under 'School.' It means that these areas still remain under researched and require further investigation.

It has been found that there are non-existing studies along extra-curricular activities and school personnel. It is considered to be a weakness of the Arab research along science education as it prevents from getting an insight into the question of equipment and supplies used in the study process, as well as school environment that may be both positive and negative. At the same time, the absence of the research on the choice of class activities, teaching methods, the use of technology while teaching, curriculum topic and flaws makes suggests that more research is needed to fully investigate and analyze the trends in the Arab research on the nature of science.

\section{Conclusions and Recommendations}

In summation, the Arab research trends indicate that the Arabic NOS is done "education through science" rather than "science through education". The discussion has identified a missing link between the curriculum, teacher's characteristics, and students' ability to grasp scientific concepts and put them into practice. Given that scientific research is the backbone of contemporary world economies, the Arab world should encourage the development of more research centers and universities, and establish institutional and cultural changes that are aimed at fostering scientific revitalization. These efforts would require the combined efforts of both local scientists and the government as adequate funding would be required. Additionally, given that science research assists governments in almost all sectors including healthcare, energy, information technology, and water. It means that collaborative efforts would foster the developed business environment and labor force. One of the measures that the governments in the Arab world should adopt is the increase in national expenditure on research and development. Apart from financial commitments, the government should also recognize the existing research and development centers, and grant them protection from religious and political debates.

On the other hand, local scientists should look at how to nurture research mentality by transferring knowledge to undergraduate and graduate students. In order to achieve this, Arab students would need to spend more practical time in the research centers, a move that can be achieved if specific projects directed towards the students are created. Again, local researchers should encourage scientific symposiums and exchanges with their counterparts from the international arena with the aim of improving scientific knowledge. This move could also be enjoined to both graduate and undergraduate students through the education exchange programs in international study programs abroad. Upon graduation, students should be given an opportunity to advance their education and develop their research. The creation of scientific centers will play a relevant role in improving the NOS and increase the number of Arab students in research, a move that will catalyze the change needed in the region. While more research has delved in identifying the nature of teaching NOS, advanced research should be developed to assess the end product of learners and their ability to tackle practical scientific and technological issues in the twenty first century.

\section{References}

Abd-El-Khalick, F. (2012).Examining the sources for our understandings about science: Enduring conflations and critical issues in research on nature of science in science education. International Journal of Science Education, 34, 353-374. https://doi.org/10.1080/09500693.2011.629013

Abd-El-Khalick, F. (2014). The evolving landscape related to assessment of nature of science. In N. Lederman, \& S. Abell (Eds.), Handbook of research in science education (pp. 621-650). New York, NY: Routledge.

Al-Omari, A., \& Nawafleh, W. (2011). The reality of science education research in Jordan in the period 
2000-2009. The Jordanian Journal of Education sciences, 7(2), 195-208.

American Psychological Association (APA). (1985). A guide to research. USA: American Psychological Association.

BouJaoude, S. (2011). Modern developments in science education. Research in Science Education, $2008,4$. Retrieved from https://www.eolss.net/sample-chapters/c11/e1-12-87.pdf

De Jong, O. (2007). Trends in western science curricula and science education research a bird's eye view. Journal of Baltic Science Education, 6(1), 15-22.

Glass, H., \& Hopkins. Y. (1984). Research method. Cambridge: Cambridge University Press.

Golato, A. (2002). German compliment responses. Journal of Pragmatics, 34, 547-571. https://doi.org/10.1016/S0378-2166(01)00040-6

Holmqvist, M., \& Olander, C. (2017). Analyzing teachers' operations when teaching students: what constitutes scientific theories? International Journal of Science Education, 39(7), 840-862. https://doi.org/10.1080/09500693.2017.1310407

Holmqvist, M. (2011). Teachers' learning in a learning study. Instructional Science, 39, 497-511. https://doi.org/10.1007/s11251-010-9138-1

James, A. (2001). The survey handbook. Thousand Oaks, CA: Sage.

Jones, M. G., Gardner, G. E., Robertson, L., \& Robert, S. (2013). Science professional learning communities: Beyond a singular view of teacher professional development. International Journal of Science Education, 35(10), 1756-1774. https://doi.org/10.1080/09500693.2013.791957

Kasper, G. (2000). Data collection in pragmatics research. In H. Spencer-Oatey (Ed.), Culturally speaking. Managing rapport through talk across cultures (pp. 316-341). London and New York: Continuum.

Lederman, N. G., \& Abell, S. K. (2014). Handbook of research on science education (Vol. 2). New York, NY: Routledge.

Lee, M. H., Wu, Y. T., \& Tsai, C. C. (2009). Research trends in science education from 2003 to 2007: A content analysis of publications in selected journals. International journal of Science Education, 31, 1999-2020. https://doi.org/10.1080/09500690802314876

Marton, F. (2015). Necessary conditions of learning. London: Routledge.

McComas, W. F. (2015). The nature of science \& the next generation of biology education. The American Biology Teacher, 77(7), 485-491. https://doi.org/10.1525/abt.2015.77.7.2

Robson, K. M. (1993). Methodological issues and problems in the assessment of substance use. Psychological Assessment, 7(3), 349-358.

Sabrini, M. \& Al Razhi, A. (1999). The reality of scientific education research in the Jordanian universities. Journal of Scientific Research, 13(1), 105-118.

Salkind, N. (2009). Exploring research. New Jersey: Upper Saddle River.

Tasi, C. C., \& Wen, M. L. (2005). Research and trends in science education from 1998 to 2002: A content analysis of publication in selected journals. The International journal of Science Education, 27(1), 3-14. https://doi.org/10.1080/0950069042000243727

Van Dijk, E. M. (2014). Understanding the heterogeneous nature of science: A comprehensive notion of PCK for scientific literacy. Science Education, 98(3), 397-411. https://doi.org/10.1002/sce.21110

Watts, R. (2003). Politeness. Cambridge: Cambridge University Press. https://doi.org/10.1017/CBO9780511615184

\section{Copyrights}

Copyright for this article is retained by the author(s), with first publication rights granted to the journal.

This is an open-access article distributed under the terms and conditions of the Creative Commons Attribution license (http://creativecommons.org/licenses/by/4.0/). 